\title{
Development of regional wheat VI-LAI models using Resourcesat-1 AWiFS data
}

\author{
Sasmita Chaurasia ${ }^{1, *}$, R Nigam ${ }^{1}$, B K Bhattacharya ${ }^{1}$, V N Sridhar ${ }^{1}$, \\ K MALlick $^{1}$, S P VYAS ${ }^{1}$, N K PATEL ${ }^{1}$, J MUKHERJEE ${ }^{2}$, \\ Chander Shekhar ${ }^{3}$, Dhiraj Kumar ${ }^{4}$, K R P Singh ${ }^{5}$, \\ G D BAIRAGi ${ }^{6}$, N L PUROHIT ${ }^{7}$ and J S PARIHAR ${ }^{1}$ \\ ${ }^{1}$ Earth, Ocean, Atmosphere, Planetary Sciences and Applications Area, \\ Space Applications Centre (ISRO), Ahmedabad 380 015, India. \\ ${ }^{2}$ Department of Agricultural Meteorology, Punjab Agricultural University, Ludhiana, India. \\ ${ }^{3}$ CCS Haryana Agricultural University, Hisar, India. \\ ${ }^{4} U P$ Remote Sensing Applications Centre, Lucknow, India. \\ ${ }^{5}$ Bihar Remote Sensing Applications Centre, Patna, India. \\ ${ }^{6}$ M.P. State Remote Sensing Applications Centre, Bhopal, India. \\ ${ }^{7}$ Rajasthan State Remote Sensing Applications Centre, Jodhpur, India. \\ ${ }^{*}$ Corresponding author.e-mail: sasmita@sac.isro.gov.in, sasmita_sac@yahoo.co.in
}

The time of forcing of spatial LAI to crop models at single or multiple stages is important to simulate crop biomass and yield in varying agro-climatic conditions and scales. The high temporal resolution (5-day) by Advanced Wide Field Sensor (AWiFS) on-board Resourcesat-1 Satellite IRS-P6 with 56 m spatial resolution and large swath $(740 \mathrm{~km})$ has substantially increased the availability of regional clear sky optical remote sensing data. The present study aimed at developing empirical vegetation index VI-LAI models for wheat using AWiFS optical data in four bands and in-situ measurements sampled over five different agro-climatic regions (ACRs) during 2005-2006 followed by validation during 2006-2007. While nonlinear relations exist for all the three normalized indices such as normalized difference vegetation index (NDVI), normalized difference water index (NDWI) and Green NDVI, linear relation was the best fit for ratio vegetation index (RVI). Both NDVI and RVI models generally showed better correlation ranges (0.65-0.84 for NDVI and $0.37-0.76$ for RVI) than other indices. The common NDVI-LAI model was found to produce lower root mean square errors (RMSE) between 0.5 and 1.1 from pooled model than those between 0.5 and 1.32 from regional models. The rate of substantial increase in errors from NDVILAI model (RMSE of modelled LAI: 0.85 to 1.28) as compared to RVI-LAI model (RMSE of modelled LAI: 1.12 to 1.17 ) at LAI greater than 3, than below 3 revealed the early saturation of NDVI than RVI. It is therefore recommended that LAI estimates can be used to force crop simulation model upto early vegetative stage based on NDVI and maximum vegetative to reproductive stages based on RVI.

\section{Introduction}

Leaf area index (LAI), defined as the one sided green leaf area per unit ground area, quantifies the amount of foliage area that controls evapotranspiration and photosynthesis as well as contributes to biomass (Maas 1991; Bonan 1993; Nemry et al 1996; Liu et al 1997). The assimilation of accurate

Keywords. Leaf area index; vegetation index. 
spatial LAI into crop models is important in simulating crop biomass and yield under varying agroclimatic conditions and spatial scales. This can be done through 'forcing' or interim correction of simulated LAI (Moulin et al 1998; Parihar and Oza 2006). The LAI forcing can be done at a single critical crop growth stage or multiple growth stages. Insitu measurements of crop specific LAI over large area are not routinely measured in farmers' fields in India but available from experimental trials in the farm plots based on the focus of specific research objectives. Satellite observations at various spatiotemporal scales in the optical wavelengths can be converted to retrieve surface reflectance and vegetation indices (VIs). These can be further used to estimate LAI either by developing simple empirical relationships (Brown et al 2000; Cihlar et al 2002) or through canopy reflectance simulation using complex physical models (Kuusk 1998; Knyazikhin et al 1999). Though regular tiled products of LAI/FAPAR (Fractional Absorbed Photosynthetically Active Radiation) are available at landscape scales $(\sim 1 \mathrm{~km})$, from MODIS (http://modis.gsfc.nasa.gov); these are more useful for assimilation into climate models or to study the biogeochemical cycles. These products are of less use to yield modelling because of moderate resolution except extensive homogeneous crop patches, where crop classification does not introduce much error.

Field scale crop LAI estimation was carried out earlier using finer resolution data $(23.5-30 \mathrm{~m})$ from the LANDSAT (Wiegand et al 1979; Price 1993; Price and Bauch 1995) and, IRS-1D LISSIII (Chaurasia et al 2006; Pandya et al 2003; Rastogi et al 2000; Singh et al 2005) satellite sensors. However, the swath width of $141-185 \mathrm{~km}$ and low temporal resolution of 16-25 days limit the use of these data for regional scale study due to cloud cover especially over the tropics (e.g., India) at the time of the overpass. The Advanced Wide Field Sensor (AWiFS) on-board IRS-P6 has a $56 \mathrm{~m}$ spatial resolution with large swath width $(740 \mathrm{~km})$ and a 5-day revisit period. The increase in temporal resolution provides more opportunity of getting clear sky satellite data for a given location. This, in turn, facilitates to widen the scope of multiple forcing through satellite-based large area crop LAI estimates to crop models (Sehgal 2001; Oza et al 2008).

Wheat (Triticum aestivum and T. durum) is the pre-dominant winter cereal in India accounting for $55 \%$ of the country's total food grain production. Wheat is grown during November to May, with crop duration of between 120 and 145 days depending on the agro-climatic regions (ACRs). In the Trans-Gangetic Plain (TGPR), Western dry (WDR), Upper Gangetic Plain (UGPR), and
Middle Gangetic Plain (MGPR) regions, wheat is sown between October and December whereas in the cental plateau and hill region (CPHR), it is sown between October and November (CMIE 2002). In MGPR and CPHR, wheat is harvested between February-May and FebruaryApril, respectively while in WDR and UGPR it is harvested between March and May. In TGPR the harvesting time is April-May (CMIE 2002). The growth response of wheat varies a lot across the ACRs depending on the genetic make-up of the cultivars, climate, soil and topographical variability. The average district wheat yield varies from 1000 to $5000 \mathrm{~kg} \mathrm{ha}^{-1}$.

The earlier VI-LAI relationships were developed by sampling over a particular location within an ACR (Pandya et al 2003; Chaurasia et al 2006). These models could not be extrapolated to other ACRs. There is a strong need to develop ACR specific VI-LAI models or a common model sampled from a variety of locations spread over different ACRs. The present study aims at developing and testing zone specific as well as common VI-LAI emipirical models for wheat crop using optical data from the AWiFS satellite sensor. Different VIs from multispectral data have been used for this purpose because of the basic assumption that some algebraic combination of the remote sensing data can tell us something useful about the state of the vegetation cover (Baret and Guyot 1991; Liang 2004) in this case the LAI.

\section{Characteristics of study regions}

Five different agro-climatic regions including six major wheat growing states (Punjab, Haryana, Rajasthan, Bihar, Uttar Pradesh and Madhya Pradesh), were considered for the study. The details of agro-climatic regions, the soil types, the wheat cultivars and the phenophases, ground measurements and satellite overpass dates are summarized in table 1( $\mathrm{a}$ and $\mathrm{b})$. Four to five homogeneous patches of wheat of more than $90,000 \mathrm{~m}^{2}$ $(300 \times 300 \mathrm{~m})$ were selected for in situ measurements in each agro-climatic region. The radial distance between two patches was kept more than $25 \mathrm{~km}$. On a given day, wheat could be at different phenological stages over different patches depending on the sowing date. In TGPR, wheat is normally grown in large contiguous patches with patch size more than $4-8$ ha (equivalent to $12-25$ AWiFS pixels) and is under irrigation. The sowing dates for different regions are also given in table 2(a). The field observations were taken in such a manner that all heterogeneity was captured within and across the agro-climatic region. The 
locations of field measurements are shown in figure 1.

\section{Methodology}

\subsection{In situ Measurements}

In situ measurements of LAI were taken using an LAI-2000 Canopy Analyzer (LICOR Inc. Nebraska). The LAI-2000 canopy analyzer is a portable field instrument simultaneously measuring diffuse radiation by fisheye technique, with the optical sensors arranged in concentric rings in five distinct angular bands, with central zenith angles of $7^{\circ}, 23^{\circ}, 38^{\circ}, 53^{\circ}$ and $68^{\circ}$. The basic technique of the measurement involves measuring the sky brightness from a leveled sensor above the canopy and the second measurement below the canopy, with the sensor viewing towards sky (Welles and Norman 1991).

A border area of $70 \times 70 \mathrm{~m}$ was left from all four sides as shown in figure 2. The central unshaded square was divided into four quadrants. Five sets of measurements were taken within central location of each quadrant and at the center of unshaded square area. Each of such five sets of measurements included one above and five below the canopy by using proper shielding. The five below-canopy measurements comprises of three within the row and two between the rows. The border area was left out to minimize the border effect on crop growth and ensure the homogeneity of the measured patch. Thus, an effective area of $160 \times 160 \mathrm{~m}$ was used for LAI measurements that approximately represents $3 \times 3$ AWiFS pixels measuring $168 \times 168 \mathrm{~m}$. The mean of five replicates represent LAI for a given patch on a given day. These were later used for model development and validation.

\subsection{Scene selection}

AWiFS images acquired only under the clearest sky conditions with average horizontal visibilities of $20 \mathrm{~km}$ (using observations from nearest IMD stations) were considered. To undertake a detailed atmospheric correction, a spatial map of aerosol optical depth (AOD) is required. The scale of operational MODIS global AOD is $1^{\circ} \times 1^{\circ}$ and, therefore, may not be suitable due to scale mismatch for this specific data. An improper value of AOD may lead to erroneous surface reflectance and lead to improper results. It has also been reported that for clearest atmospheric conditions the VI from topof-atmosphere (TOA) reflectance are equivalent to those derived from surface reflectance (Liang 2004). Thus the TOA reflectance was used for further analysis. 
Table 1(b). Details of field observations and satellite data acquisitions for the analysis.

\begin{tabular}{|c|c|c|}
\hline $\begin{array}{l}\text { Agro-climatic regions } \\
\text { (states) }\end{array}$ & $\begin{array}{c}\text { Dates of clear AWiFS } \\
\text { coverages }\end{array}$ & $\begin{array}{l}\text { Period of field } \\
\text { campaign }\end{array}$ \\
\hline \multirow[t]{6}{*}{ CPHR (Madhya Pradesh) } & 12 December 2005 & 12-16 December 2005 \\
\hline & 29 January 2006 & 25-29 January 2006 \\
\hline & 12 December 2006 & 12-16 December 2006 \\
\hline & 5 January 2007 & 4-8 January 2007 \\
\hline & 17 February 2007 & 5-9 February 2007 \\
\hline & 13 March 2007 & 11-14 March 2007 \\
\hline \multirow[t]{5}{*}{ WDR (Rajasthan) } & 14 January 2006 & 11-15 January 2006 \\
\hline & 21 February 2006 & 21-23 February 2006 \\
\hline & 25 December 2006 & 24-26 December 2006 \\
\hline & 23 January 2007 & 23-25 January 2007 \\
\hline & 16 February 2007 & 15-17 February 2007 \\
\hline \multirow[t]{6}{*}{ MGPR (Bihar) } & 6 January 2006 & 6-8 January 2006 \\
\hline & 25 January 2007 & 5-7 February 2006 \\
\hline & 18 February 2007 & 6-8 March 2006 \\
\hline & 9 March 2007 & 24-25 January 2007 \\
\hline & & 14-15 February 2007 \\
\hline & & 7-8 March 2007 \\
\hline \multirow[t]{13}{*}{ TGPR (Punjab, Haryana) } & 9 January 2006 & 3-5 January 2006 \\
\hline & 2 February 2006 & 31 January-2 February 2006 \\
\hline & 3 March 2006 & 7-8 March 2006 \\
\hline & 13 January 2007 & 9-10 January 2006 \\
\hline & 2 February 2007 & 26-28 February 2006 \\
\hline & 26 February 2007 & 9-11 January 2007 \\
\hline & 22 March 2007 & 2-4 February 2007 \\
\hline & 4 January 2007 & 26-28 February 2007 \\
\hline & 28 January 2007 & 22-24 March 2007 \\
\hline & 21 February 2007 & 3-5 January 2007 \\
\hline & 17 March 2007 & 27-29 January 2007 \\
\hline & & 20-22 February 2007 \\
\hline & & 16-18 March 2007 \\
\hline \multirow[t]{7}{*}{ UGPR (Uttar Pradesh) } & 10 January 2006 & 2-4 January 2006 \\
\hline & 3 February 2006 & 2-4 February 2006 \\
\hline & 10 January 2007 & 1-3 March 2006 \\
\hline & 3 February 2007 & 8-12 January 2007 \\
\hline & 27 February 2007 & 31 January-3 February 2007 \\
\hline & 23 March 2007 & 26 February-2 March 2007 \\
\hline & & 19-23 March 2007 \\
\hline
\end{tabular}

CPHR: Central plateau and hill region; WDR: Western dry region; MGPR: Middle Gangetic Plain region; TGPR: Trans-Gangetic Plain region; UGPR: Upper Gangetic Plain region.

\subsection{Computation of reflectance}

The digital number $(D N)$ in green $(0.52-0.59 \mu \mathrm{m})$, red $(0.62-0.68 \mu \mathrm{m})$, near infrared (NIR) $(0.77-0.86$ $\mu \mathrm{m})$ and short wave infrared (SWIR) (1.55-1.7 $\mu \mathrm{m})$ bands of AWiFS were converted to at-sensor radiance using equation (1)

$$
L_{\mathrm{TOA} i}(\lambda)=\frac{\left(D N_{i}(\lambda)-\text { offset }\right)}{\text { Gain }}
$$

$L_{\mathrm{TOA} i}(\lambda)$ is the at sensor TOA radiance in $\mathrm{Wm}^{-2} \mathrm{Sr}^{-1} \mu \mathrm{m}^{-1}$ of $i$ th pixel for a given band $(\lambda)$,
$D N$ represents digital number of $i$ th pixel. The TOA radiance can be converted into TOA reflectance as:

$$
\rho=\frac{\pi d^{2} L_{\mathrm{TOA} i}(\lambda)}{E_{0}(\lambda) \cos \left(\theta_{s}\right)}
$$

where, $\rho$ is the TOA reflectance, $d$ is the mean sun-earth distance correction factor, $E_{0}$ is the exoatmospheric solar irradiance $\left(\mathrm{Wm}^{-2} \mu \mathrm{m}^{-1}\right)$, and $\theta_{s}$ is the solar zenith angle in radian. The solar zenith angle was generated from the image header information. The $E_{0}$ values were computed using the 
Table 2(a). Exponential model $\left[L A I=a^{*} \exp \left(b^{*} V I\right)\right]$ coefficients for wheat LAI estimation using three normalized indices over different ACRs.

\begin{tabular}{|c|c|c|c|c|}
\hline \multirow[b]{2}{*}{ ACRs } & \multirow[b]{2}{*}{ Vegetation indices } & \multicolumn{2}{|c|}{ Model coefficients } & \multirow[b]{2}{*}{$R^{2}$} \\
\hline & & $a$ & $b$ & \\
\hline \multirow[t]{3}{*}{ CPHR } & NDVI & 0.078 & 5.362 & 0.72 \\
\hline & NDWI & 0.402 & 5.464 & 0.70 \\
\hline & Green NDVI & 0.135 & 6.260 & 0.67 \\
\hline \multirow[t]{3}{*}{ UGPR } & NDVI & 0.049 & 7.370 & 0.79 \\
\hline & NDWI & 0.215 & 8.610 & 0.72 \\
\hline & Green NDVI & 0.102 & 8.140 & 0.79 \\
\hline \multirow[t]{3}{*}{ TGPR } & NDVI & 0.019 & 7.370 & 0.71 \\
\hline & NDWI & 0.148 & 7.370 & 0.60 \\
\hline & Green NDVI & 0.088 & 6.988 & 0.60 \\
\hline \multirow[t]{3}{*}{ WDR } & NDVI & 0.138 & 4.823 & 0.84 \\
\hline & NDWI & 1.135 & 2.979 & 0.61 \\
\hline & Green NDVI & 0.213 & 5.424 & 0.83 \\
\hline \multirow[t]{3}{*}{ MGPR } & NDVI & 0.162 & 5.179 & 0.65 \\
\hline & NDWI & 0.782 & 3.294 & 0.37 \\
\hline & Green NDVI & 0.247 & 6.259 & 0.58 \\
\hline
\end{tabular}

relative spectral response data for the green, red, NIR and SWIR AWiFS detectors as outlined by Pandya et al (2007).

\subsection{Computation of vegetation indices (VIs)}

Homogeneous wheat patches comprising $3 \times 3$ pixels over the measurement sites were marked as region of interest (ROI) on AWiFS scene using Geographical Positioning System (GPS) (Magellan NAVDLX-10) co-ordinates and Survey of India (SOI) topographic maps. The Normalized Difference Vegetation Index (NDVI) (Rouse et al 1974), Normalized Difference Water Index (NDWI) (Gao 1996), GreenNDVI (Gitelson et al 1996) and Ratio Vegetation Index (RVI) or Simple Ratio (SR) (Pearson and Miller 1972), were computed using combinations of reflectance $(\rho)$ in green, red, NIR

Table 2(b). Linear model [LAI=a*RVI+b] coefficients for wheat LAI estimation over different ACRs.

\begin{tabular}{lccc}
\hline & \multicolumn{2}{c}{ Model coefficients } & \\
\cline { 2 - 3 } ACRs & $a$ & $b$ & $R^{2}$ \\
\hline CPHR & 0.743 & -0.964 & 0.76 \\
UGPR & 1.569 & -2.374 & 0.72 \\
TGPR & 0.714 & -0.669 & 0.37 \\
WDR & 0.850 & -0.846 & 0.76 \\
MGPR & 0.896 & -0.890 & 0.67 \\
\hline
\end{tabular}

and SWIR bands. The formulae used were as follows:

$$
\begin{gathered}
\text { NDVI }=\frac{\rho_{\text {NIR }}-\rho_{\text {red }}}{\rho_{\text {NIR }}+\rho_{\text {red }}} \\
\text { NDWI }=\frac{\rho_{\text {NIR }}-\rho_{\text {SWIR }}}{\rho_{\text {NIR }}+\rho_{\text {SWIR }}} \\
\text { GreenNDVI }=\frac{\rho_{\text {NIR }}-\rho_{\text {green }}}{\rho_{\text {NIR }}+\rho_{\text {green }}} \\
\text { RVI }=\frac{\rho_{\text {NIR }}}{\rho_{\text {red }}}
\end{gathered}
$$

with the exception of RVI which is a ratio index, all other VIs are normalized indices. The choice of NDVI and RVI is based on the increased contrast in spectral reflectances in red and NIR bands with increase in leaf area and canopy growth. However, RVI is more contaminated by background soil reflectances than NDVI at early growth stages (Liang 2004). The NDWI is basically sensitive to changes in canopy water content as compared to pigments and mesophyll structure. It was found that the incorporation of SWIR band reduces the background effect (Zheng and Moskal 2009). Moreover, NDWI is directly correlated to canopy dry matter development upto flowering stage which is an indicator of leaf area development specially in cereal crops (Yi et al 2007). The uncertain space weathering sometimes deteriorates band specific 


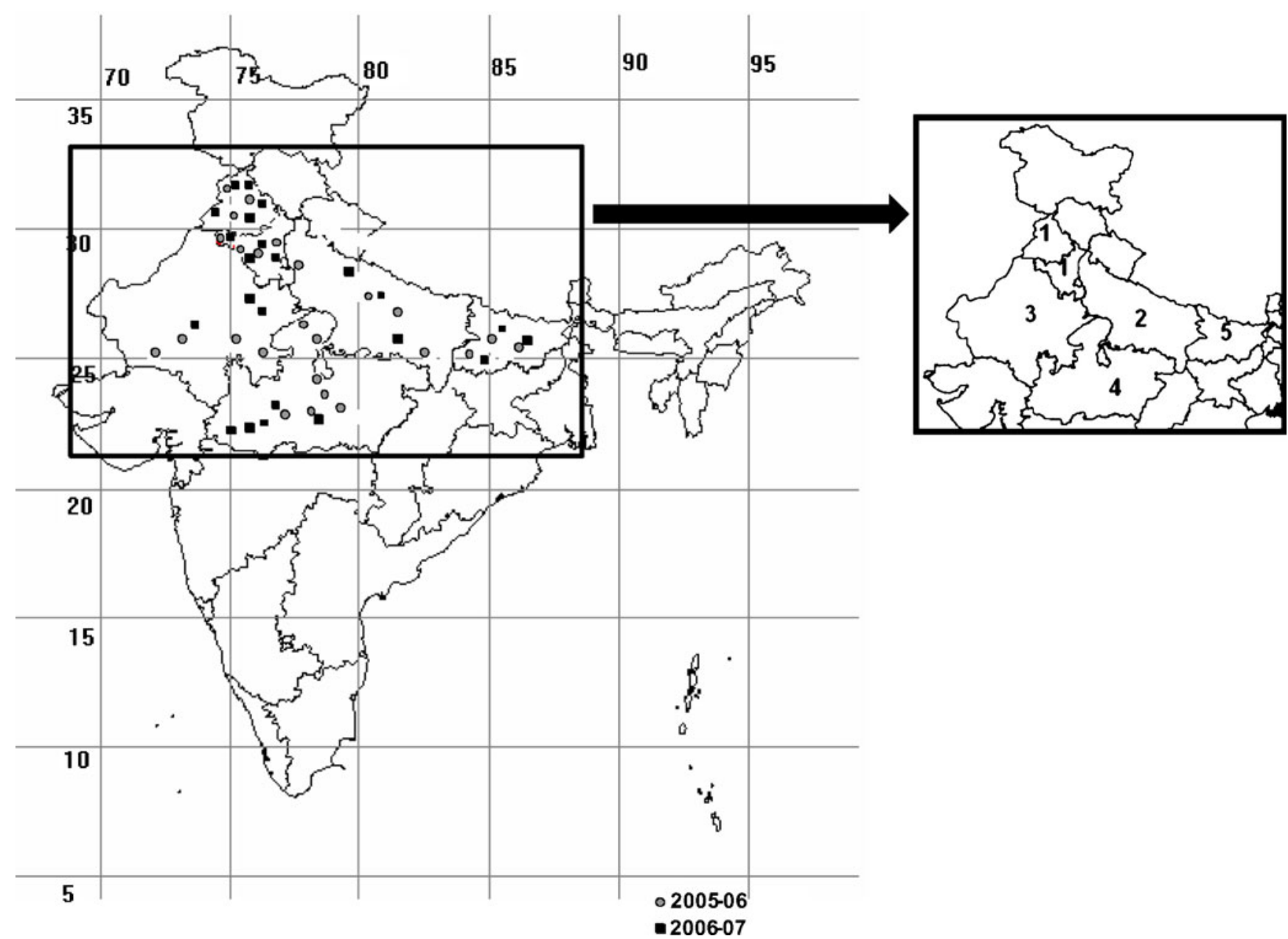

Figure 1. Left side figure shows the distribution of sampling locations ( $O$ 2005-2006 used for development of model and - 2006-2007 used for validation) and right side figure shows the corresponding agro-climatic regions (ACRs). 1. TGPR, 2. UGPR, 3. WDR, 4. CPHR, and 5. MGPR.

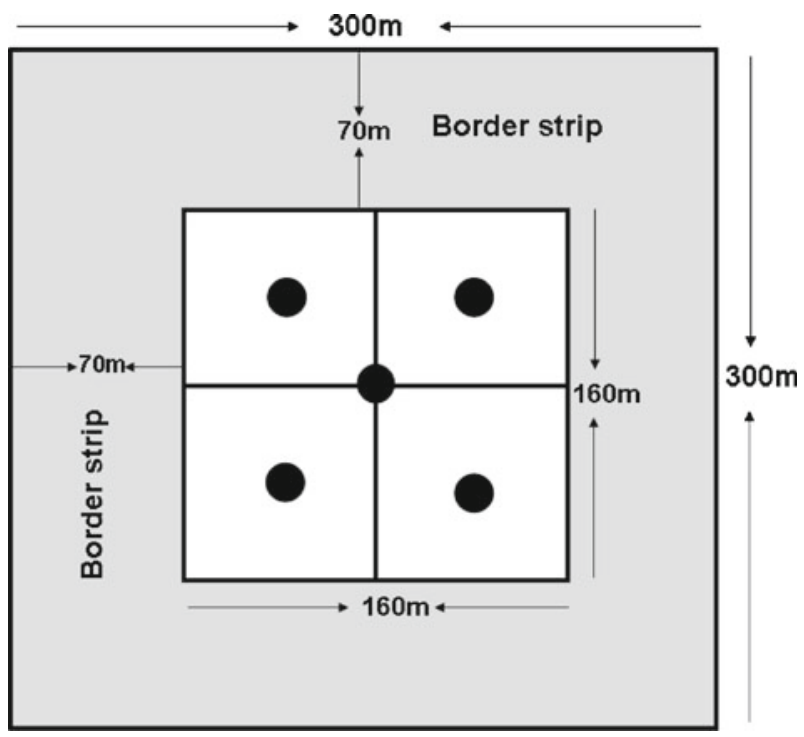

Figure 2. Field sampling design showing the locations of field measurements in dark circles within a $300 \times 300 \mathrm{~m}$ selected wheat patch. filters in the satellite sensors which are beyond control to rectify. Therefore, LAI models based on VIs from all combinations of four bands are required to be prepared to use them judiciously for operational crop forecast. A comparative evaluation of these models based on different VIs is needed to judge the different aspects of their usability. Regression models were developed between the measured LAI and different vegetation indices for wheat over different ACRs separately, as well as with pooled datasets. The flowchart for the generation of LAI is given in figure 3 .

\subsection{Geo-registration and wheat mask generation}

Template geo-referencing of the AWiFS image was adopted with reference to $\left(2^{\circ} \times 2^{\circ}\right)$ LISS (Linear Imaging Self Scanner) III tiles through VADS (Value Added Data Software) developed by the Signal and Image Processing Group (SIPG) at Space Applications Centre (SAC). The software 


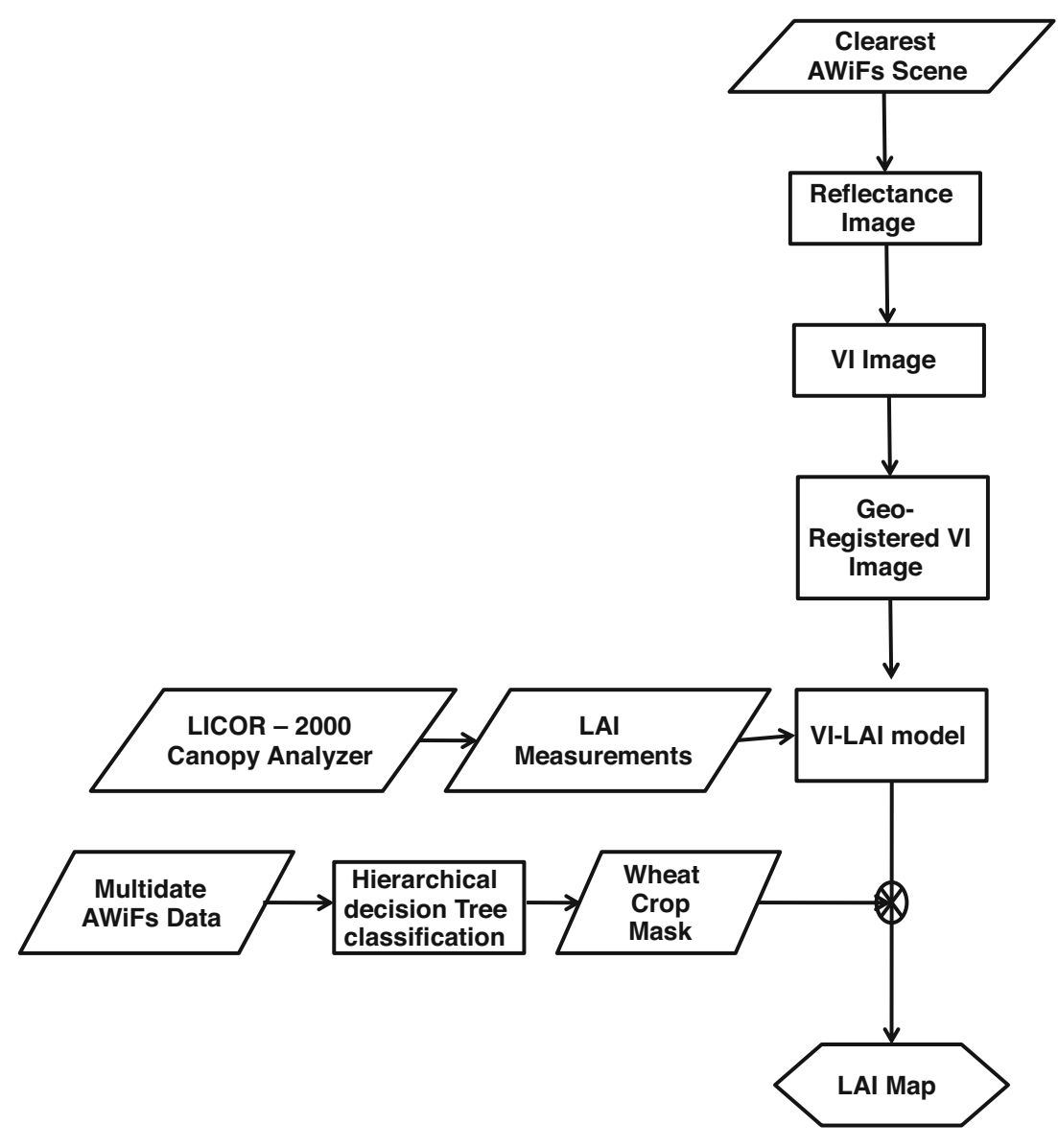

Figure 3. Flowchart for the generation of LAI map.

accepts base template data from $2^{\circ} \times 2^{\circ}$ tiles in 'Tagged Interleaved File Format' (TIFF). The base IRS-1D LISS III $(\sim 24 \mathrm{~m})$ subtiles were obtained from RSDB project (Rajak et al 2006). The master LISS III image in 'Tiff' format was transferred to the VADS software to prepare a geo-referenced template of the AWiFS image. The multidate data were co-registered with the AWiFS master image with a root mean square error (RMSE) within \pm 0.5 pixels. The wheat crop mask generated using multidate AWiFS data and a hierarchical decision rule classifier as a part of National Wheat Production Forecast (NWPF) project (Oza et al 2006) was used in this study.

\section{Results and discussion}

\subsection{VI-LAI empirical models}

The 2005-2006 data were used to develop the empirical relationships between the VIs and the ground measurements of LAI. An exponential relationship was found to be better than a linear relationship for the three normalized indices (NDVI,
NDWI, GreenNDVI). The model coefficients $(a, b)$ and the correlation coefficients for three normalized VI over different ACRs are summarized in table 2(a). However, a linear relationship appeared to show a better correlation than an exponential relationship for the RVI. The model coefficients (a, b) for the linear model between RVI and LAI are given in table 2(b) for the different ACRs.

Among all the VIs, RVI and NDVI were found to have consistent higher correlation as compared to other indices. NDVI produced a relatively better correlation $\left(R^{2}=0.65-0.84\right)$ over all the ACRs as compared to RVI $\left(R^{2}=0.37-0.76\right)$. With less plant density, RVI is highly sensitive to background soil reflectance as well as canopy growth stages (Nayak 2005). Moreover, it is also most sensitive to atmospheric haze and topography. The NDVI is the commonly preferred index for extracting biophysical properties of vegetation, because it is relatively insensitive to background soil reflectance, and is less affected by atmospheric conditions and topographical variations. There is a relative disadvantage of NDVI saturation at higher LAI values (Smith et al 2005) as compared to RVI which mean that NDVI is not appropriate in the discrimination of high-density covers (Srinivas et al 


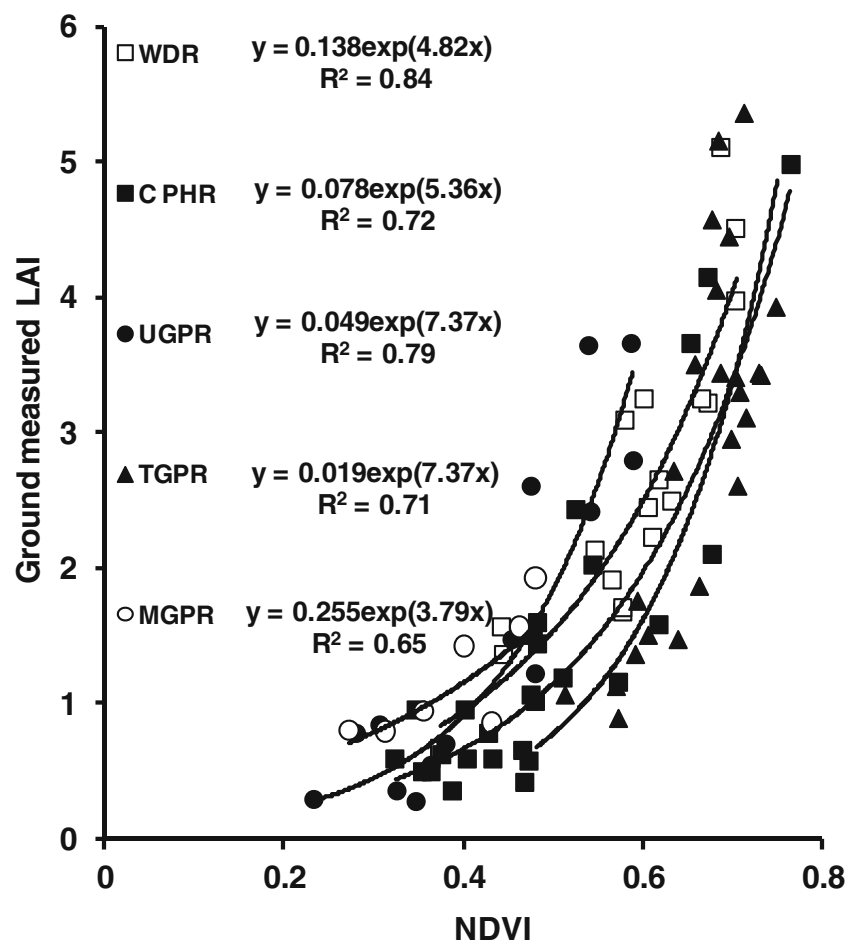

Figure 4. The relationship between AWiFS derived NDVI and wheat LAI for five different agro-climatic regions over India (2005-2006).

2004). The LAI-NDVI plots with their associated model curves for the various ACRs are shown in figure 4. It was found that the model curves were not well segregated regionwise. Therefore, an

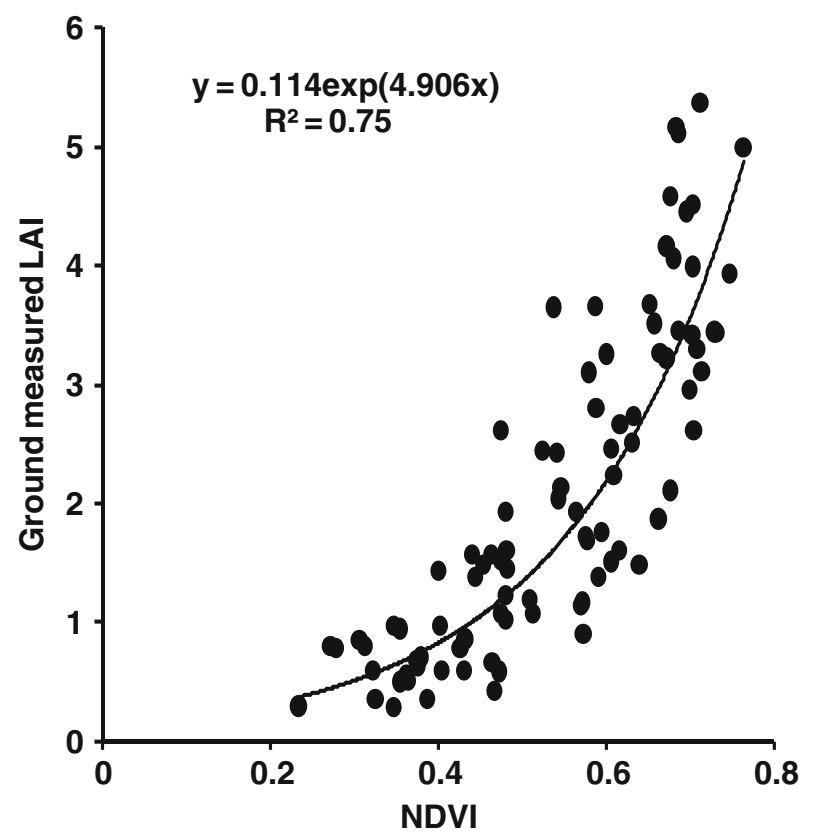

Figure 5. The relationship between AWiFS derived NDVI and wheat LAI using pooled datasets sampled over all the five agro-climatic regions over India.

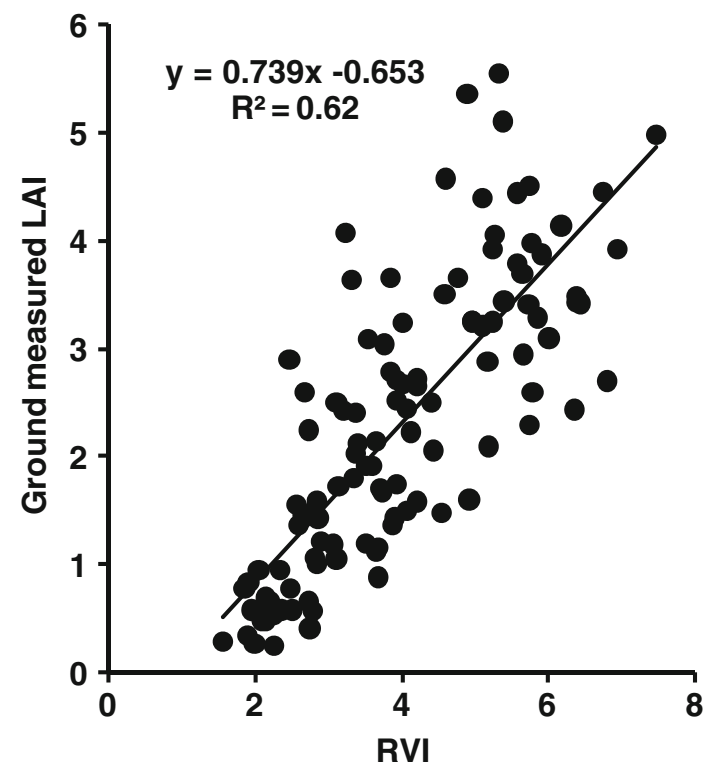

Figure 6. The relationship between AWiFS derived RVI and wheat LAI using pooled datasets sampled over all the five agro-climatic regions over India.

exponential model involving the data from all the five ACRs was, developed between the measured LAI and NDVI (figure 5) and the LAI and RVI (figure 6). Among all the VIs, NDWI was found to result in the lowest correlation $\left(R^{2}=0.37-0.70\right)$ with wheat LAI in all ACRs. The NDWI is related to the canopy water content. It is also influenced by soil moisture conditions such that a higher NDWI may not mean a higher LAI (Liang 2004).

\subsection{Validation of NDVI-LAI model}

The regional NDVI-LAI empirical models developed for five ACRs and the pooled model were validated with in situ measurements collected during the post-rainy season of 2006-2007. The validation statistics using both the region specific and pooled model coefficients are shown in tables 4 and 5. The regional model for TGPR (table 3 ) shows an RMSE

Table 3. Error statistics for estimation of LAI for 20062007 using region specific LAI-NDVI model developed using 2005-2006 data.

\begin{tabular}{lccc}
\hline ACRs & $n$ & $R^{2}$ & RMSE \\
\hline TGPR & 94 & 0.52 & 1.35 \\
WDR & 15 & 0.49 & 0.7 \\
UGPR & 47 & 0.46 & 1.1 \\
CPHR & 31 & 0.76 & 0.5 \\
MGPR & 36 & 0.45 & 1.0 \\
\hline
\end{tabular}

where, $n$ is number of observations.

$\operatorname{RMSE}=\sqrt{\left(\sum(\mathrm{LAI}(\text { measured })-\mathrm{LAI}(\text { estimated }))^{2} / n\right)}$. 
Table 4. Error statistics for estimation of LAI from NDVI for 2006-2007 over different ACRs using pooled model developed using 2005-2006 data.

\begin{tabular}{lccc}
\hline ACRs & $n$ & $R^{2}$ & RMSE \\
\hline TGPR & 94 & 0.57 & 0.76 \\
WDR & 15 & 0.60 & 0.77 \\
UPGR & 47 & 0.54 & 1.00 \\
CPHR & 31 & 0.74 & 0.50 \\
MGPR & 36 & 0.42 & 1.10 \\
\hline
\end{tabular}

of 1.35 ( $45.7 \%$ of measured mean) and a correlation of 0.52 . The pooled model showed a lower RMSE of 0.76 (25.9\% of measured mean) but the same correlation $\left(R^{2}=0.52\right)$. The responses of leaf area growth to different agro-climatic settings in wheat growing belt could have been captured in the pooled model as compared to regional model. This could strengthen the predictive power of pooled model resulting into lower RMSE while correlation depends on range of paired (estimated and measured) LAI datasets. The regional model for WDR produced an RMSE of $0.7(34.8 \%)$ with $R^{2}=0.49$. The pooled model showed an RMSE (0.77) with $R^{2}=0.60$ (table 4 ). The LAI in the WDR was generally underestimated LAI using both models. The regional model for UGPR (table 3) showed a correlation of 0.46 with an RMSE of 1.1 (47.1\%). The correlation improved to 0.54 using the pooled model while the RMSE was similar. In CPHR, the regional model produced correlation coefficient of 0.76 and an RMSE of 0.5. The pooled model showed similar results for both the RMSE (0.5) and $R^{2}=0.74$. In MGPR, the regional model showed slightly lower RMSE as compared to pooled model. Both the models produced similar correlation in the range of $0.42-0.45$.

It is evident that the pooled NDVI based model performed better in three of the five ACRs (TGPR, WDR and UGPR) while in the other two ACRs (CPHR and MGPR) the pooled model performed similar to the regional model. Figure 7 shows the $1: 1$ validation plot of the LAI estimates and the measurements sampled over all the ACRs. It produced an overall RMSE in the order of 0.88 and $R^{2}=0.55$.

\subsection{Comparison of NDVI-based pooled LAI model with RVI-based model over different LAI classes}

The LAI estimation accuracy from the NDVI was evaluated for four LAI classes $(<1, \geq 1$ to $<2$, $\geq 2$ to $\leq 3,>3$ ) and the errors compared with those from the RVI-based model for all the classes. The error statistics are summarized in table 5. Up to an LAI of 3 , the RMSE in LAI estimates were lower with the NDVI (0.43-0.85)

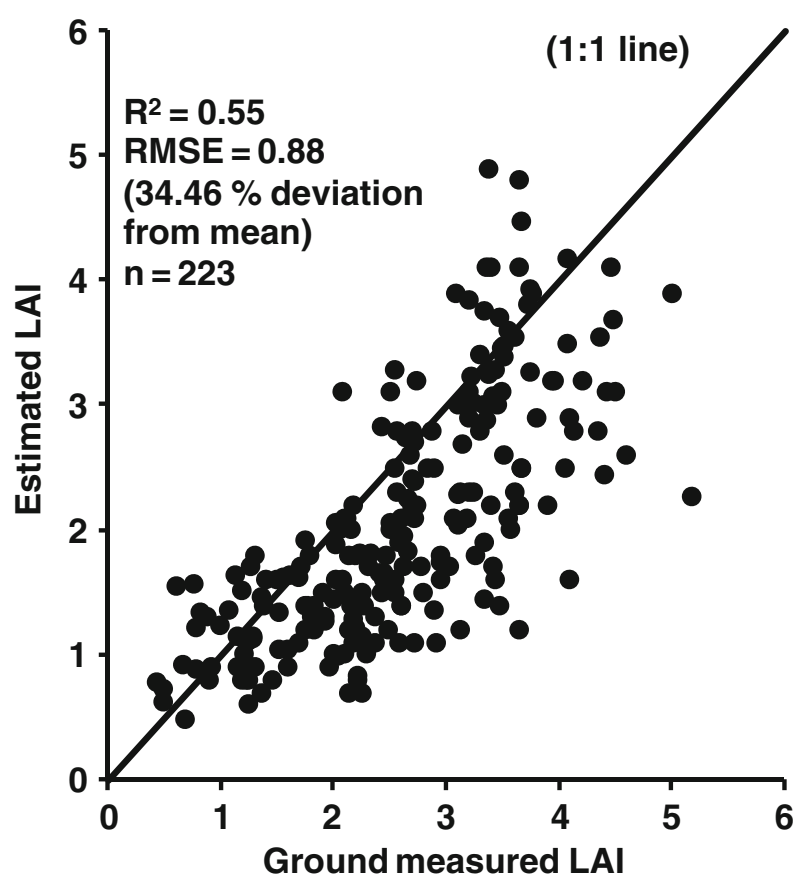

Figure 7. Validation of pooled NDVI-LAI model using data from all agro-climatic regions.

Table 5. Root mean square error for different LAI classes using pooled model with NDVI and RVI for all ACRs.

\begin{tabular}{lccc}
\hline LAI range & $n$ & $\begin{array}{c}\text { RMSE } \\
\left(\text { LAI }_{\text {NDVI }}\right)^{*}\end{array}$ & $\begin{array}{c}\text { RMSE } \\
\left(\mathrm{LAI}_{\mathrm{RVI}}\right)^{*}\end{array}$ \\
\hline$<1$ & 14 & 0.43 & 0.61 \\
$\geq 1$ to $<2$ & 47 & 0.44 & 0.71 \\
$>2$ to $\leq 3$ & 82 & 0.85 & 1.12 \\
$>3$ & 70 & 1.28 & 1.17 \\
\hline
\end{tabular}

${ }^{*} \mathrm{LAI}_{\mathrm{NDVI}}$ is the LAI estimated using NDVI-LAI model, $\mathrm{LAI}_{\mathrm{RVI}}$ is the LAI estimated using RVI-LAI model.

as compared to RVI model (0.61-1.12). The magnitude of errors for both the models generally increased with an increase in LAI levels, but the rate of increase became substantially higher with the NDVI after the LAI reached 2 as compared to that with the RVI. The NDVI-based model produced a lower RMSE (0.43-0.44) as compared to the RVI model (0.61-0.71) up to an LAI of 2 . It is important to note that for NDVI greater than 3 , the RMSE from the RVI model (1.17) was lower than that from the NDVI (1.28). The NDVI tends to become saturated earlier than RVI (Liang 2004). The red reflectance comes from single leaf layer whereas the NIR reflectance comes from multiple leaf layers. Therefore, red saturates faster than the NIR reflectance. In NDVI computation, most of the changes can be attributed to the red band (Teillet et al 1997) while in the case of the RVI which 

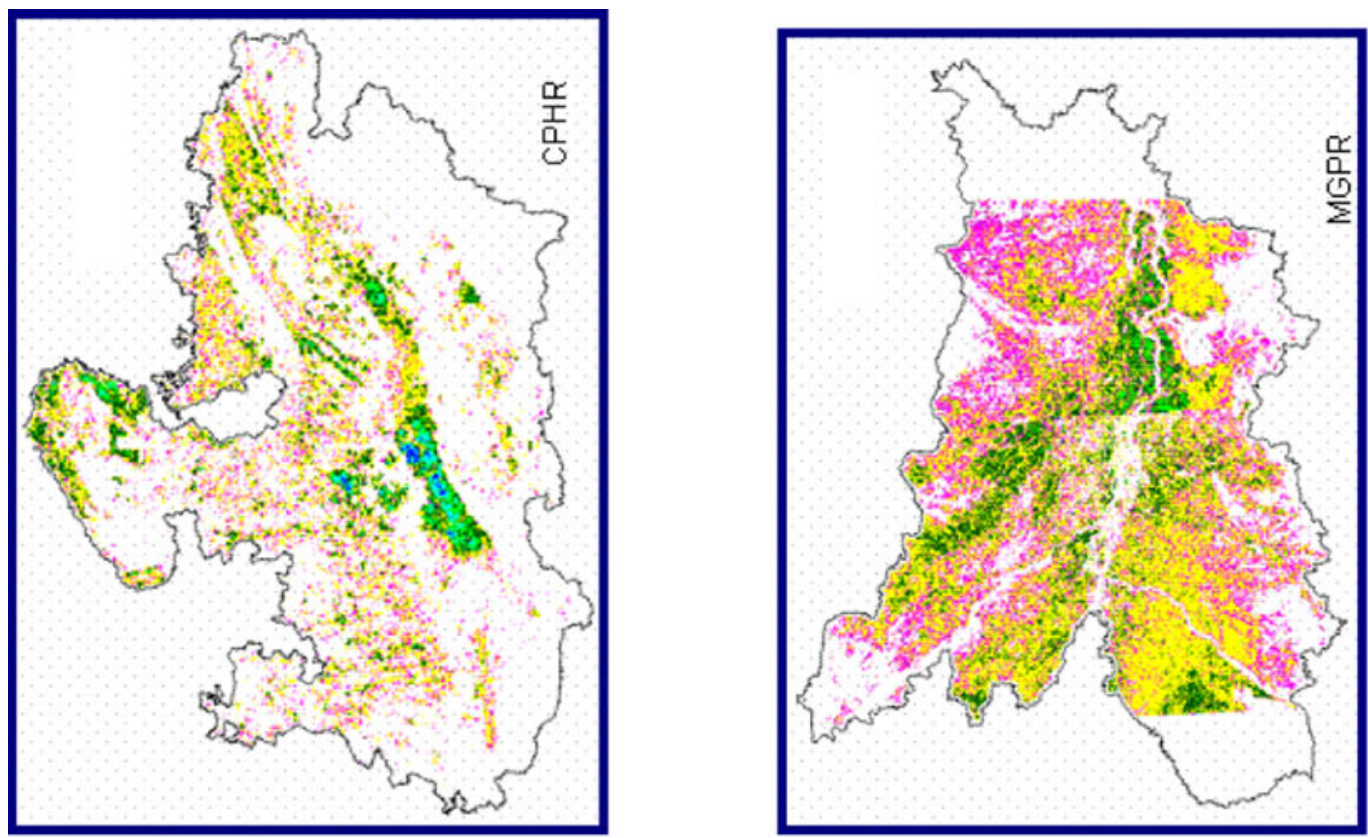

舟

స్.
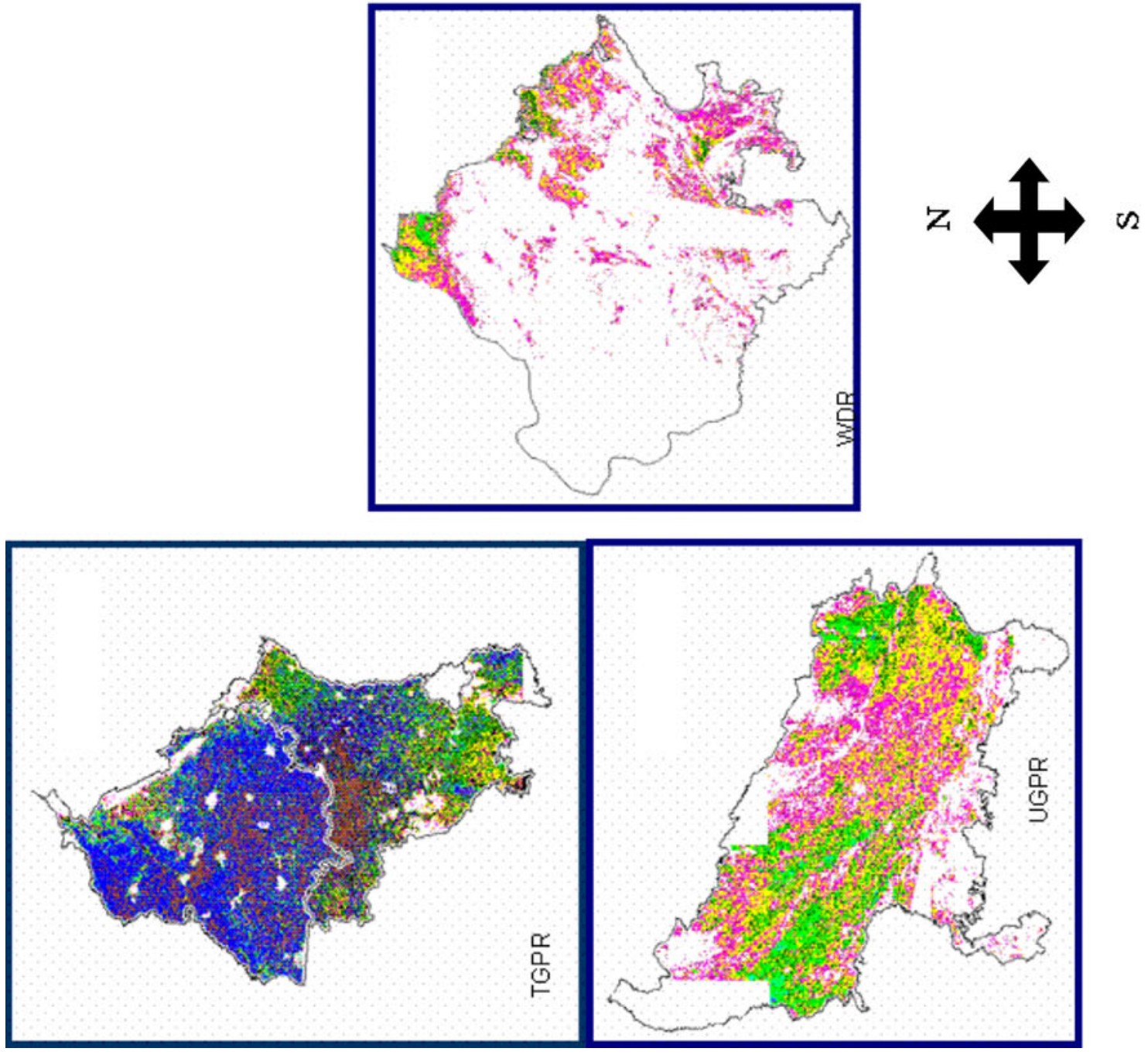

总

은 듈

ণ্்

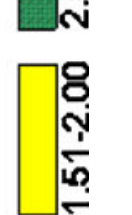

$1 \begin{array}{ll}0 \\ 0\end{array}$

䁶

员 曋

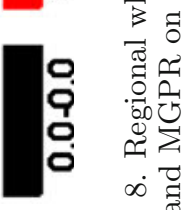


is a simple ratio of the NIR and red reflectance, the value continues to increase to a larger extent as the canopy grows. Therefore, the RMSE of the LAI estimates from RVI are lower than those from the NDVI-based estimates at higher canopy growth levels. It would be wise to estimate LAI from NDVI for values less than 3 which generally corresponds to wheat at maximum tillering stage. At peak vegetative to reproductive stages, RVI-based estimates are better preferred for model forcing.

Previous studies with space-borne remote sensing data indicated that empirical LAI estimation has generally large RMSE. The two stream model of Price (1993) applied to LISS (Linear Imaging and Self-scanning)-III data (23.5 m resolution) over a wheat crop resulted in an RMSE of 0.78 and 1.23 for LAI with ranges 1-4 and 4-6, respectively (Rastogi et al 2000). Estimation of LAI with RVI and the reduced simple ratio (RSR) incorporating the SWIR channel for crops produced RMSE of 1.10 and 2.00, respectively (Chen et al 2002) using National Oceanic and Atmospheric Administration (NOAA) Advanced Very High Resolution Radiometer (AVHRR) data over Canada. Pandya et al (2003) reported an RMSE of 0.92 and 1.26 with reference to the MODIS LAI product for two different dates of observations over Bhopal in CPHR. Our earlier analysis using LISS-III, which is single-site specific (Chaurasia et al 2006) produced an RMSE of 0.698 for LAI estimated using the RVI, and 0.689 for LAI estimated using NDVI. The work reported by Pandya et al (2003) and Chaurasia et al (2006) are site specific and thus could not be extrapolated over large region. The present common wheat VI-LAI empirical model developed and evaluated from samples over a variety of agro-climatic regions as well as growth stages is operationally feasible with AWiFS data for regional wheat growth modelling until improved LAI modelling schemes are tested and tuned for Indian conditions.

The distributed output of regional wheat LAI estimates from an NDVI-based common model during peak vegetative stage over the five ACRs is shown in figure 7 . Though the variability in LAI was large (1.0-5.0) over the wheat growing belt, the majority of the pixels showed an estimated LAI range between 3.0 and 5.0. In TGPR, LAI varied from 1.0 to 5.0. During the same time, UGPR shows a higher variability between 0.51 and 4.50 . In the WDR, $60 \%$ of the wheat cover had an LAI in the range of 1.0 to 2.0. In CPHR, the LAI ranges from 1.0 to 4.5. The higher LAI range in TGPR than WDR and CPHR could be due to more intensification through higher irrigation water availability, fertilizers and relatively longer persistence of low temperature (figure 8).

\section{Summary and conclusions}

The unique contribution of the above study is the development and validation of regionally applicable VI-based wheat LAI models with a large number of samples over a variety of agro-climatic settings and growth stages. The NDVI and RVIbased empirical models are exponential and linear, respectively with almost similar correlations. The NDVI-based LAI estimates were found to produce lower errors for LAI less than 2, but the errors increased above an LAI of 2 with the rate of increase being higher for the NDVI than the RVI. At LAI greater than 3, the RVI-based model produced less errors compared to the NDVI model. The reasons are explained in relation to canopy density and index saturation. LAI classwise error analysis was able to provide the choice of models for LAI forcing depending on the wheat phenophases. Presently, regional LAI estimates at 100\% panicle stage (around February) using such models with AWiFS data are being routinely used to a crop simulation model, WOFOST, for its spatial implementation to forecast pre-harvest wheat yield at state and national scales. Further scope exists to improve these empirical models using multiple regression with multiple vegetation indices. But saturation of vegetation indices at higher LAI is the major limitation of regression models. Moreover, revision of model coefficients are required after a certain interval to take account of crop response to deviations of environmental conditions from their long term mean. Therefore, physical inversion approach of canopy radiative transfer simulation using surface reflectances would be ideal to retrieve LAI to eliminate such limitations.

\section{Acknowledgements}

The authors are thankful to Dr R R Navalgund, Director, Space Applications Centre for encouragement. They are also thankful to the National Wheat Production Forecast (NWPF) Team members at Space Applications Centre, Ahmedabad for providing the geo-registered AWiFS data and wheat crop mask.

\section{References}

Baret F and Guyot G 1991 Potential and limits of vegetation indices for LAI and APAR assessment; Rem. Sens. Env. 35 161-173.

Bonan G 1993 Importance of leaf area index and forest type when estimating photosynthesis in boreal forests; Rem. Sens. Env. 43 303-314.

Brown L, Chen J M, Leblanc S G and Cihlar J 2000 A shortwave infrared modification to the simple ratio for LAI 
retrieval in boreal forests: An image and model analysis; Rem. Sens. Env. 71 16-25.

CMIE (Center for Monitoring Indian Economy private limited), December 2002, India, pp. 53-56.

Chaurasia S, Bhattacharya B K, Dadhwal V K and Parihar J S 2006 Field-scale Leaf Area Index estimation using IRS-1D LISS-III data; Int. J. Rem. Sens. 27(4) 637-644.

Chen J M, Pavlic G, Brown L, Cihlar J, Leblanc S G, White H P, Hall R J, Peddle D R, King D J, Trofymow J A, Swift E, Van der Sanden J and Pellikka P K E 2002 Derivation and validation of Canada-wide coarse-resolution leaf area index maps using high-resolution satellite imagery and ground measurements, Rem. Sens. Env. 80 165-184.

Cihlar J, Chen J, Li Z, Latifovic R, Fedosejevs G, Adair M, Park W, Raser R, Trishchenko A, Guindon B, Stanley D and Morse D 2002 GeoComp-n, an advanced system for the processing of coarse and medium resolution satellite data. Part: Biophysical products for northern ecosystems; Can. J. Rem. Sens. 28 21-44.

Gao B 1996 NDWI-A normalized difference water index for remote sensing of vegetation liquid water from space; Rem. Sens. Env. 58 257-266.

Gitelson A A, Kaufman Y J and Merzlyak M N 1996 Use of a green channel in remote sensing of global vegetation from EOS-MODIS; Rem. Sens. Env. 58 289-298.

Knyazikhin Y, Glassy J, Privette J L, Tian Y, Lotsch A, Zhang Y, Wang Y, Morisette J T, Votava P, Myneni R B, Nemani R R and Running S W 1999 MODIS leaf area index (LAI) and fraction of photosynthetically active radiation absorbed by vegetation (FAPAR) product (MOD15) algorithm basis document; Available online at http://esopso.gsfc.nasa.gov/atbd/modistables. html.

Kuusk A 1998 Monitoring of vegetation parameters on large areas by the inversion of a canopy reflectance model; Int J. Rem. Sens. 19(15) 2893-2905.

Liang S 2004 Quantitative Remote Sensing of Land Surfaces; Wiley Interscience.

Liu J, Chen J M, Cihlar J and Park W M 1997 A processbased Boreal ecosystem productivity simulator using remote sensing inputs; Rem. Sens. Env. 62 158-175.

Maas S J 1991 Use of remotely sensed information in plant growth simulation models; Adv. Agron. 1 17-26.

Moulin S, Bandeau A and Delecolle R 1998 Combining agricultural crop models and satellite observations: From field to regional scales; Int. J. Rem. Sens. 19 1021-1036.

Nayak S S 2005 Thermal imagery and spectral reflectance based system to monitor crop condition; M.S. Thesis, Texas Tech University.

Nemry B, Francois L, Warnant P, Robinet F and Gerard J C 1996 The seasonality of the $\mathrm{CO}_{2}$ exchange between the atmosphere and the land biosphere: A study with global mechanistic vegetation model; J. Geophys. Res. 101 7111-7125.

Oza M P, Pandya M R and Rajak D R 2008 Evaluation and use of Resourcesat-I data for agricultural applications; Int. J. Appl. Earth Obs. Geo. Inf. 10 194-205.

Oza M P, Rajak D R, Bhagia N, Dutta S, Vyas S P, Patel N K and Parihar J S 2006 Multiple production forecasts of wheat in India using remote sensing and weather data; Proceedings of SPIE $\mathbf{6 4 1 1} 641,102-641,108$.

Pandya M R, Chaudhuri K N, Singh R P, Sehgal V K, Bairagi G D, Sharma R and Dadhwal V K 2003 Leaf area index retrieval using IRS LISS-III sensor data and validation of MODIS LAI product over Madhya Pradesh; Curr. Sci. 85(12) 1777-1782.

Pandya M R, Singh R P, Chaudhuri K N, Murali K R, Kirankumar A S, Dadhwal V K and Parihar J S 2007 Spectral characteristics of sensors onboard IRS-1D and P6 satellites: Estimation and their influence on surface reflectance and NDVI; Indian J. Rem. Sens. 35(4) $333-350$.

Parihar J S and Oza M P 2006 FASAL: An integrated approach for crop assessment and production forecasting; Proceedings of SPIE 6411 641,101-641,113, doi: 10.1117/ 12.713157.

Pearson R L and Miller L D 1972 Remote mapping of standing crop biomass for estimation of the productivity of strong grass prairie. Pawnee National Grasslands, Colorado; Proceedings of the 8th International Symposium on Remote Sensing Environment II 1355-1379.

Price J C 1993 Estimating leaf area index from satellite data; IEEE Trans. Geosci. Rem. Sens. 31(3) 727-734.

Price J C and Bauch W C 1995 Leaf area index estimation from visible and near-infrared reflectance data; Rem. Sens. Env. 52 55-65.

Rajak D R, Bhuyan M R, Oza M P, Patel N K and Parihar J S 2006 Remote sensing database preparation from IRS data and LULC change monitoring over Indo-Gangetic basin; International Archives of the Photogrammetry, Remote Sensing 85 Spatial Information Sciences, Vol. 36, Part 4, "Geospatial databases for Sustainable Development", Goa, September 27-30, 2006, India.

Rastogi A, Kalra N, Agrawal P K, Sharma S K, Harit R C, Navalgund R R and Dadhwal V K 2000 Estimation of wheat leaf area index from IRS LISS-III data using Price model; Int. J. Rem. Sens. 21(15) 2943-2949.

Rouse J W, Has R H, Schell J A, Deering D W and Harlan J C 1974 Monitoring the vernal advancement of retrodgradation of natural vegetation; NASA/GSFC, Type III, Final Report, Greenbelt, MD, 371p.

Sehgal V K, Rajak D R and Dadhwal V K 2001 Issues in linking remote sensing inputs in a crop growth monitoring system: Results of a case study; In: Proc. ISRS National Symposium, December 11-13, 2001, Ahmedabad, India.

Singh R P, Dadhwal V K, Singh K P, Navalgund R R, Sharma R, Bairagi G D, Raza S A and Sharma N K 2005 Retrieval of wheat leaf area index using Price approach based on inversion of canopy reflectance model; J. Indian Soc. Remote Sens. 33(2) 307-313.

Smith A M, Nadeau C, Freemantle J, Wehn H, Teillet P M, Kehler I, Daub N, Bourgeois G and De Jong R 2005 Leaf area index from CHRIS satellite data and applications in plant yield estimation; 26th Canadian symposium on Remote Sensing Wolfville, Nova Scotia.

Srinivas P, Das B K, Saibaba J and Krishnan R 2004 Application of distance based vegetation index for agricultural crops discrimination; XXth ISPRS Congress, Commission 7, Istanbul, Turkey.

Teillet P M, Staenz K and Williams D J 1997 Effects of spectral, spatial and radiometric characteristics on remote sensing vegetation indices of forested region; Rem. Sens. Env. 61 139-149.

Yi Y, Yang D, Chen D and Huang J 2007 Retrieving crop physiological parameters and assessing water deficiency using MODIS data during the winter wheat growing period; Can. J. Rem. Sens. 33(3) 189-202. 
Welles J M and Norman J M 1991 Instrument for indirect measurement of canopy architecture; Agron. J. 83 818-825.

Wiegand C L, Richardson A J and Kanemasu E T 1979 Leaf area index estimates for wheat from LANDSAT and their implications for evapotranspiration and crop modeling; Agron. J. 71 336-342.

Zheng G and Moskal L M 2009 Retrieving leaf area index using remote sensing: Theories, methods, sensors; Sensors $92719-2745$.

MS received 23 May 2010; revised 8 August 2011; accepted 11 August 2011 